\title{
Perception against COVID-19 Threat Affecting the Behavior of Indonesia People Three Months after the Outbreak
}

\author{
Putri C. Eyanoer ${ }^{1 \star}$, Farhat Farhat ${ }^{2}$, Elvita Rahmi Daulay ${ }^{3}$, Fotarisman Zaluchu ${ }^{4}$ \\ ${ }^{1}$ Department of Community and Preventive Medicine, Faculty of Medicine, Universitas Sumatera Utara, Medan, Indonesia; \\ ${ }^{2}$ Department of Otorhinolaryngology, Head and Neck Surgery, Faculty of Medicine, Universitas Sumatera Utara, Medan, \\ Indonesia; ${ }^{3}$ Department of Radiology, Faculty of Medicine, Universitas Sumatera Utara, Medan, Indonesia; ${ }^{4}$ Department of \\ Epidemiology, Faculty of Public Health, Universitas Sumatera Utara, Medan, Indonesia
}

Edited by: Mirko Spirosk Citation: Eyanoer PC, Farhat F, Daulay ER, Zaluchu Perception against COVID-19 Threat Affecting th Behavior of Indonesia People Three Months after the Outbreak. Open Access Maced J Med Sci. 2020 Nov 07
8(T1):459-464. https://doi.org/10.3889/oamjms.2020.5432 Keywords: Adaptation of new behavior; Perceived vulnerability; Perceived severity Correspondence: Putri C.Eyanoer, Department of Community and Preventive Medicine, Faculty of Medicine, Universitas Sumatera Utara, Indonesia. E-mail: putrieyanoer@usu.ac.id Received: $11-\mathrm{Sep}-2020$ Accepted: 28-Oct-2020

Copyright: ๑ 2020 Putri C. Eyanoer, Farhat Farhat, Elvita Rahmi Daulay, Fotarisman Zaluchu Funding: Publication of this article was financially Funding: Publication of this article was financially
supported by the Scientific Foundation SPIROSKI, Skopje, Republic of Macedonia Competing Interests: The authors have declared that no
competing interests exist Competing Interests: The authors have declared that no
competing interests exist under the terms of the Creative Commons AttributionNonCommercial 4.0 International License (CC BY-NC 4.0)

\section{Introduction}

COVID-19 has not only stopped in the China region, called Wuhan, in which the first case of this violent outbreak was reported. In a brief period, there is no continent free from the outbreak insurgence [1], resulting in the emergence of 85.959 cases reported by the World Health Organization (WHO) at the end of February 2020. COVID-19 outbreak has escalated 3 times for 1 month by infecting six million people in May 2020, and finally, more than 40 million people diagnosed with COVID-19 and more than a million deaths on October 21, 2020 [2].

WHO regional office in South-East Asia (SEARO) is also involved in the reporting of the outbreak. In early February, there were only 100 confirmed cases. Still, it rose to more than two million people infected in this region at the end of July and ranked South East Asia as the third position for the highest COVID-19 cases after America and Europe [2].

In Indonesia, the first case was officially reported by the Ministry of Health in early March 2020. After the first case, the outbreak became more vigorous in the incidence and attracted international concern. Three months after the first case's announcement, there were 26.473 cases with a six percent mortality rate related to COVID-19. Until last July 2020, more than 100.000 people contracted, and 4.975 deaths were confirmed with the infection [3].

New behavior has been introduced in the community to prevent COVID-19 transmission following 3 months of the COVID-19 outbreak [4]. The Ministry of Health, Republic of Indonesia, also names this new concept as "the adaptation of new behavior." The exemplification of these concepts starts from the recommendation to use facemasks when performing outdoor activities, proper hand-washing with soap or disinfectant frequently, keeping the distance, and avoiding mass gatherings. Furthermore, the government also encourages people to implement a healthy lifestyle by adequately consuming nutritious food and vitamins to boost the immune system [5].

Efforts to contain COVID-19 transmission need coordination for the national campaign by establishing the special task force. This task force works in the national until regional/city level all over Indonesia with the central vision of ensuring citizen compliance abided 
to the health protocol previously aired by the government from several routes such as social media and television. Until recently, the government has continued to deliver health communication, reminded the public to maintain discipline on government recommendations, and reported essential developments in preventing COVID19 transmission.

However, all preventive measures and health protocols encouraged by the government have not yet yielded any significant impact on reducing the COVID19 positivity rate. This unsuccessful outcome indicates that infective circulation is still occurring caused by incompliant to the health protocol.

Rule enforcement is necessary to create a supportive environment for implementation. Still, community perception against COVID-19 has more critical effects on producing good practice since positive perception would generally bear positive outcomes/ behavior [6]. Therefore, the evaluation of perception could be a beneficial approach.

Health belief model (HBM) is one of the concepts for the determination of community perception against COVID-19. In HBM, there are six things that drive a person's behavior, namely perceived susceptibility, perceived severity, perceived benefits, perceived barriers, perceived self-efficacy, and clues to action. With the HBM model, it is assumed that if a person has the view that he is susceptible to the severity of COVID-19, then he will interpret the recommended benefits more than the perceived barriers. Then, the person will have self-efficacy that he will act (clues to action). Thus, two basic things are important to know, namely, perceived susceptibility and perceived severity. Both of them are commonly mentioned as "threat perception" [7]. These two things will be used as indicators in carrying out this research.

Although the HBM concept has been used extensively in a variety of health studies, in the context of COVID-19, there is still very little theoretical guidance in this latest health issue [8]. The application of the HBM concept in conceiving community behavior against COVID-19 has been utilized previously. Therefore, extensification is necessary to adjust varied conditions existing in other regions/countries.

The application of the HBM concept in conceiving community behavior against COVID-19 has been utilized previously. Therefore, extensification is necessary to adjust varied conditions existing in other regions/countries.

Thus, measuring community perceptions against COVID19 at the individual level is essential. This study would supply feedback to the existing point that could represent the gap for COVID-19 health communication and disclosing consistency between perception and community behavior.

\section{Materials and Methods}

\section{Sample}

The study was designed cross-sectional, which was conducted through sharing online links. Respondents must exceed 17 years old and participated in the questionnaire filling for 4 weeks, between May 18 , 2020 , and June 19, 2020. A total of 1687 respondents $(99.5 \%)$ respondents consent for study enrollment from 1696 respondents originated from all over Indonesia. The respondent data relating to name, address, or other personal identities were keep confidential and has been approved by the research committee.

\section{Questionnaire}

The questionnaire consists of a study explanation, informed consent, and questions. There are two sub-sections in the question section, such as identity/demography (gender, marital status, age, and source of information) and implemented-health practice. Questions about health practice were scrutinized in the previous 2 months. It includes asking hand-washing, facemasks, mass gatherings avoidance, hand-sanitizer application, and nutritious food/vitamin consumption (government recommendation).

The question regarding HBM asks two perceptions, namely perception of self-vulnerability and COVID-19 severity, and there are six questions for each perception. Thus, there are a total of 12 questions asked of each respondent. The time needed to complete the questionnaire was less than $1 \mathrm{~min}$. The arrangement of questions was following three options such as "agree" would be scored two, one for "do not know," and zero for "disagree." The readability of the questionnaire was tested against 30 people before online dissemination.

The summation of scores in each primary perception would be grouped into two types of interpretations. Perceptions of self-vulnerability were divided into "susceptible to contract" for a total score of 8-10, and vice versa, "not susceptible" was indicated by $0-7$ scores. Meanwhile, perception of severity was grouped into "COVID-19 is severe" for a minimum score of eight and "not severe" for a score ranging from zero and seven.

Six questions determined the interpretation of behavior, and each question consisted of answers with four options such as "always," "rarely," "when remembering," and "never." Under the government recommendations, everyone is obliged to implement three vital behaviors. It must be performed by respondents, including hand-washing with soap, using facemasks, and avoiding mass gatherings. Respondents abided to the three behaviors simultaneously would be stated as "suited to 
recommendations." Meanwhile, respondents who only applied one behavior, or even though they implement other health practices outside of the three mandatory behavior, would be categorized as "not suited to recommendations." The Cronbach's alpha for 12 questions is 0.783 , indicates a high level of internal consistency for this questionnaire.

\section{Platform}

The questionnaire was designed and disseminated using a Google form since this platform was easy to access by respondents. Furthermore, a survey model using Google form is wide-spread in terms of both familiarity and reproducibility for onlinebased-survey. Google forms could also be distributed just in a brief period through rapid link sharing using copy-paste shortcuts to other social media platforms, including the WhatsApp group.

\section{Data processing and statistical analysis}

Data were analyzed descriptively in the form of a frequency distribution. The Chi-square test continued further analysis to determine the difference in perception with respondents' behavior, while the statistical significance degree used $p<0.05$ in the study.

\section{Results}

\section{Demographic characteristics}

A total of $67.8 \%$ of respondents was female from 1678 people approved for study enrollment. Table 1 depicts more than half of the respondents are married, and the largest proportion is in the age group of $21-30$ years old (35.8\%) and $31-40$ years old $(29.9 \%)$. Besides, respondent access for the information about COVID-19 varied, but the most familiar line is WhatsApp group/private lines, followed by television/radio, $83.5 \%$ and $80.6 \%$, respectively.

Table 1: Demographic characteristics of respondents

\begin{tabular}{lll}
\hline Characteristics & $\mathrm{n}$ & $\%$ \\
\hline Gender & & \\
$\quad$ Male & 544 & 32.2 \\
$\quad$ Female & 1143 & 67.8 \\
Marriage status & & \\
$\quad$ Unmarried & 711 & 42.1 \\
Married & 949 & 56.3 \\
$\quad$ Widow/-er & 27 & 1.6 \\
Age groups (years old) & & \\
<20 & 182 & 10.8 \\
$21-30$ & 604 & 35.8 \\
$31-40$ & 505 & 29.9 \\
$41-50$ & 315 & 18.7 \\
$51-60$ & 74 & 4.4 \\
$>60$ & 7 & 0.4 \\
Information access about COVID-19 & & 80.6 \\
$\quad$ TV/radio & 1359 & 71.0 \\
Newspaper/ print/online magazine & 1197 & 83.6 \\
WhatsApp group/ personal chat & 1410 & 75.0 \\
Facebook & 1265 & 82.6 \\
$\quad$ Other social media & 1393 & \\
\hline
\end{tabular}

\section{Practice/behavior}

Table 2 shows the pattern of respondents' health practices as recommended by the government. Several behaviors were performed as "always" in the previous 3 months, dominated by the practice of using facemasks (92.9\%) and hand-washing (90.2\%). Meanwhile, vitamin consumption, using hand-sanitizer, and avoiding mass gatherings were only complied by $49.6 \%, 63.1 \%$, and $88.4 \%$ of respondents.

Table 2: Respondents' health practice/behavior to prevent COVID-19 transmission

\begin{tabular}{lllll}
\hline $\begin{array}{l}\text { Implemented-behavior for } \\
\text { the previous 3 months }\end{array}$ & Always (\%) & Rarely (\%) & $\begin{array}{l}\text { When } \\
\text { remembering (\%) }\end{array}$ & Never (\%) \\
\hline $\begin{array}{l}\text { Hand-washing with soap } \\
\text { after performing outdoor }\end{array}$ & 90.2 & 4.7 & 5.0 & 0.1 \\
$\begin{array}{l}\text { activities } \\
\text { Using hand-sanitizer }\end{array}$ & 63.1 & 26.9 & 7.6 & 2.4 \\
$\begin{array}{l}\text { Using facemasks } \\
\text { Avoiding mass gatherings }\end{array}$ & 92.9 & 4.7 & 2.4 & 0.1 \\
$\begin{array}{l}\text { Nutritious food and vitamin } \\
\text { consumption }\end{array}$ & 49.6 & 9.5 & 1.7 & 0.4 \\
\hline
\end{tabular}

\section{Perception}

In the study, there were two perceptions becoming the aims of the questions. First, respondents' perception of self-vulnerability contracting COVID-19 was demonstrated in Table 3. There were $71.4 \%$ of respondents who answered agree that self-vulnerability of getting COVID-19 is because of frequent interaction outside the home, but "agree" was answered for getting an infection because of not using a facemask by $56.3 \%$. Meanwhile, only $47.2 \%$ of respondents stated that living in a similar region/city with sufferers also a source of self-vulnerability.

Table 3: Respondents' perception of self-vulnerability for contracting COVID-19

\begin{tabular}{|c|c|c|c|}
\hline Variables & Agree & Do not know & Disagree \\
\hline If not wearing facemasks & $950(56.3)$ & $94(5.6)$ & $643(38.1)$ \\
\hline Because frequently interact outside the home & $1205(71.4)$ & $110(6.5)$ & $372(22.1)$ \\
\hline $\begin{array}{l}\text { Because living in similar places/ } \\
\text { neighborhood with health workers }\end{array}$ & $588(34.9)$ & $215(12.7)$ & 884 (52.4) \\
\hline $\begin{array}{l}\text { Because living in similar places/ } \\
\text { neighborhood with died COVID-19 patients }\end{array}$ & $734(43.5)$ & $178(10.6)$ & 775 (45.9) \\
\hline In one region/city with COVID-19 patients. & $797(47.2)$ & $194(11.5)$ & $696(41.3)$ \\
\hline
\end{tabular}

The second perception was shown in Table 4, and the results for evaluation are more homogenous than the self-vulnerability perception. For instance, $90.0 \%$ of respondents agree for the fact that they could get infection involuntarily and vice versa, transmit the virus without prior knowledge of being infected, and $88.5 \%$ of respondents answered "agree" for the statement. A total of $85.4 \%$ of respondents agreed if the family and his-/herself could be contracted with COVID-19. Moreover, $86.7 \%$ of respondents realized that COVID-19 was more severe if its sufferers were ill with other comorbidities. The awareness of COVID-19 severity was reflected by the agreement of $83.6 \%$ of respondents if COVID-19 could cause fatality/deaths.

Table 4: Respondents' perception of COVID-19's severity

\begin{tabular}{llll}
\hline Variables & Agree & Do not know & Disagree \\
\hline Family and his-/herself could be infected & $1441(85.4)$ & $113(6.7)$ & $133(7.9)$ \\
Infected involuntarily & $1534(90.9)$ & $86(5.1)$ & $67(4.0)$ \\
Severe if it was ill with comorbidity & $1463(86.7)$ & $103(6.1)$ & $121(7.2)$ \\
Could cause fatalities/deaths & $1411(83.6)$ & $89(5.3)$ & $187(11.1)$ \\
Could transmit involuntarily & $1493(88.5)$ & $101(6.0)$ & $93(5.5)$ \\
\hline
\end{tabular}


From Chi-square analysis, there were $81.7 \%$ of respondents who had a perception of "susceptible to contract" performed behavior suited to recommendations, as suggested by government. At the same time, a total of $81.2 \%$ study population had a perception of "COVID-19 is severe" executed behavior suited to the recommendation. Based on statistical analysis, perception of COVID-19 severity had a significant result in the behavior $(p<0.05)$, as depicted in Table 5.

Table 5: Statistical analysis for perception and behavior among respondents

\begin{tabular}{|c|c|c|c|}
\hline \multirow[t]{2}{*}{ Perception } & \multicolumn{2}{|l|}{ Behavior } & \multirow[t]{2}{*}{$\mathrm{p}$} \\
\hline & $\begin{array}{l}\text { Suited to } \\
\text { recommendations }\end{array}$ & $\begin{array}{l}\text { Not suited to } \\
\text { recommendations }\end{array}$ & \\
\hline \multicolumn{4}{|l|}{ Self-vulnerability } \\
\hline Vulnerable & $518(81.7)$ & $116(18.3)$ & \multirow[t]{2}{*}{0.196} \\
\hline Not vulnerable & $833(79.1)$ & $220(20.9)$ & \\
\hline \multicolumn{4}{|l|}{ COVID-19 severity } \\
\hline COVID-19 is severe & $1171(81.2)$ & $272(18.8)$ & \multirow[t]{2}{*}{$0.008^{*}$} \\
\hline Not severe & $180(73.8)$ & $64(26.2)$ & \\
\hline
\end{tabular}

\section{Discussion}

This study utilized the basic concept of HBM, threat perception so that it could unravel that perception of the family- and self-vulnerability as well as COVID19 severity highly determine respondents' behavior. As depicted in Table 5, respondents who conceived that they were vulnerable to getting the infection and at the same time strictly abided to the government recommendation, such as hand-washing with soap, using facemasks, and avoiding mass gatherings; however, it was insignificantly related $(p=0.196)$. Other than that, if the respondents grasped the perspective that COVID-19 is severe, they also performed the recommendation $(p<0.05)$.

The two-factual basis demonstrated that perception has a strong association with health behavior or practices. In a study, there was also a significant relationship between the behavior of using health insurance and the perception of seriousness and susceptibility of developing several health conditions among young adults as its users [9]. Meanwhile, the suboptimal of health practices in the targeted-population was conversely related to several studies' adequate perception levels [10], [11]. Thus, this perception study does not only appear as the tools to scrutinize the current event for the behavior evaluation or the use of healthcare facilities, but it could also be used as a predictor for health behavior/practices in the future [7], [12].

In other words, the positive or good perception could attain the betterment of behavior/ practices. On the contrary, negative perception is complicated to the achievement of the desired behavior. Tackling COVID19 needs implementation of new behaviors, but some people were reluctant to perform the behavior, or it has never been done before. For 3 months, people's behavior reflected that there was difficulty in enforcing the behavior. Indeed, this condition was also related to threat perception that is not present among every community member.

In addition, respondents' perceptions also represent some potential problems, and it needs prompt management with effective communication. Referring to Table 3, most respondents have insights that her-/himself would be more vulnerable if they were not using facemasks and having interaction outside the home. Nevertheless, both statements were agreed only by a percentage of $56.3 \%$ and $71.4 \%$ of respondents for each. Conversely, there were $38.1 \%$ of respondents disagree with the fact that using facemasks reducing transmissibility, and $22.1 \%$ of respondents also disagreed that self-vulnerability to contract from the infection occurred through frequent interaction outside the home. This condition demonstrated that the perspective against the importance of using facemasks and the people who had frequent interactions outside the home still need attention.

Furthermore, there was a significant mortality rate among COVID-19 patients in the country. Nevertheless, there were still about $40 \%$ of the respondents who disagree with the fact that a higher possibility of getting COVID-19 would ensue if they did not abide by the government recommendation. The negligence of the perception would become the primary source of problems since it let the people ignore the recommendation and, at the same time, increase the positivity rate in the community; the preventive measures only rely on the recommendations as it acknowledges that no vaccine is available until the mid-year of 2021.

However, perception of COVID-19 severity was evident, having higher coverage for "COVID-19 is severe"; all questions for this perception agreed by almost $80 \%$ of respondents. The statement for the respondents could be infected involuntarily was agreed by $91 \%$ of respondents. Nevertheless, $11.1 \%$ of respondents disagree with the severity of COVID19 could cause deaths, and $8 \%$ of respondents also disagreed with the statement that she/he and her/his family could get the infection. This item of question would be related to most of the respondents' perception in Table 3 disclosed that they were not vulnerable to COVID-19 infection, although no facemasks were used and not in their home.

Moreover, identifying essential steps in alleviating the burden of COVID-19 transmissibility is inevitable, and findings for the information gap about COVID-19; therefore, this current study would answer those aims. The question structure given to the respondents disclosed several aspects that need urgent management by the government. Similar to previous studies [13], [14], assessment against aspects of individual perception would ease further intervention. For the people in the intervention targeted-group, assessment of item perceptions cautiously would yield more positive behavior [15]. A more advanced approach 
was performed in which the items of respondents' perception then put as the background for intervention, continued by comparison studies using the randomized controlled trial [16].

Following the study's context, respondents' perception of responding to this pandemic served as a genuine problem if they wrongly understood it. Still, it could be transformed by good deliverance of information to the people comprehensively and accurately, and it finally turns the community into becoming more knowledgeable. The current dissemination of any information is more convenient since a wide variety of platforms could be deployed (Table 1). More than $50 \%$ of respondents were also in the age group of $21-40$ years old, who stated as the generation with easy exposure for information.

This research reveals only two basic ideas of HBM theory in the context of COVID-19, which some may consider weak. More thorough research on the HBM theory may produce better pictures of individual perception on COVID-19. In addition, analysis of other aspects outside HBM theory may explain a better formation of individual behavior. However, the information gathered from this study is very useful in changing people's perceptions which identified still inadequate after the COVID-19 pandemic occurred for almost a year. Although the study was conducted to picture a 3 months period after the pandemic occurred, it can be stated that there is no significant difference on the perceptions of COVID-19 since it is obvious there are no changes in people's behavior up to present.

\section{Conclusion}

Based on the author's knowledge, this is the first study conducted in Indonesia using "threat perception" as the main approach for revealing people's behavior. This study finally demonstrated the establishment of government recommendations, and several factual bases for COVID-19 infection did not guarantee the actual health practice/behavior in the community. The existing misconception of the perspective of seriousness/ severity and susceptibility would prevent the country from "flattening the curve." Therefore, this study becomes evident that there is a need for the government to emphasize enforcing and encouraging for the changes in people's perspective and, lastly, behavior.

\section{References}

1. World Health Organization. COVID-19 Strategic Preparedness and Response Plan, Country Preparedness and Response
Status for COVID-19 Country as of 19 March 2020. Geneva: World Health Organization; 2020. Available from: https://www. who.int/publications/m/item/updated-country-preparednessand-response-status-for-covid-19-as-of-19-march-2020. [Last accessed on 2020 Aug 29].

2. World Health Organization. COVID-19 Weekly Epidemiological Update. Geneva: World Health Organization; 2020. Available from: https://www.who.int/docs/default-source/coronaviruse/ situation-reports/20201020-weekly-epi-update-10.pdf. [Last accessed on 2020 Oct 21].

3. Ministry of Health. Situasi Terkini Perkembangan Covid-19; 2020. Available from: https://www.covid19.kemkes.go.id/ situasi-infeksi-emerging/info-corona-virus/situasi-terkiniperkembangan-coronavirus-disease-covid-19-31-juli-2020. [Last accessed on 2020 Aug 01].

4. Centers for Disease Control and Prevention. CDC Activities and Initiatives Supporting the COVID-19 Response and the President's Plan for Opening America Up Again. Georgia, United States: Centers for Disease Control and Prevention; 2020. Available from: https://www.cdc.gov/coronavirus/2019-ncov/ downloads/community-mitigation-strategy.pdf [Last accessed on 2020 Aug 29].

5. Ministry of Health. Pedoman Pencegahan dan Pengendalian Covid-19; 2020. Available from: https://www.covid19. go.id/p/protokol/pedoman-pencegahan-dan-pengendaliancoronavirus-disease-covid-19-revisi-ke-5. [Last accessed on 2020 Aug 20].

6. Hwang JH, Lim CH, Kim DH, Eun BW, Jo DS, Song YH, et al. A survey of parental perception and pattern of action in response to influenza-like illness in their children: Including healthcare use and vaccination in Korea. J. Korean Med Sci. 2017;32(2):20411. https://doi.org/10.3346/jkms.2017.32.2.204

PMid:28049230

7. Tajeri M, Raheli H, Zarifian S, Yazdanpanah M. The power of the health belief model (HBM) to predict water demand management: A case study of farmers' water conservation in Iran. J Environ Manage. 2020;263:110388. https://doi. org/10.1016/j.jenvman.2020.110388

PMid:32174529

8. Jose R, Narendran M, Bindu A, Beevi N, Manju L, Benny PV. Public perception and preparedness for the pandemic COVID 19: A health belief model approach. Clin Epidemiol Glob Health. 2020;2020:1-9. https://doi.org/10.1016/j.cegh.2020.06.009

9. Luquis RR, Kensinger WS. Applying the health belief model to assess prevention services among young adults. Int $\mathrm{J}$ Health Promot Educ. 2019;57(1):37-47. https://doi.org/10.1080/14635 240.2018.1549958

10. Ma C. An investigation of factors influencing self-care behaviors in young and middle-aged adults with hypertension based on a health belief model. Heart Lung. 2018;47(2):136-41. https://doi. org/10.1016/j.hrtlng.2017.12.001

PMid:29395265

11. Juárez-garcía DM, de Jesús García-Solís M, Téllez A Adaptation and validation of the health belief model scale for breast self-examination in Mexican women. Value Health Reg Issues. 2020;23:30-6. https://doi.org/10.1016/j.vhri.2019.11.006 PMid:32498024

12. Ashoori F, Karimi M, Mokarami H, Seif M. Using health belief model to predict oral health behaviors in girl students: A structural equation modeling. Pediatr Dent J. 2020;30(1):24-32. https://doi.org/10.1016/j.pdj.2019.12.001

13. James DC, Pobee JW, Oxidine D, Brown L, Joshi G. Using the health belief model to develop culturally appropriate weight-management materials for African-American women. $J$ Acad Nutr Diet. 2012;112(5):664-70. https://doi.org/10.1016/j. jand.2012.02.003 


\section{PMid:22709771}

14. Wu S, Feng $X$, Sun $X$. Development and evaluation of the health belief model scale for exercise. Int J Nurs Sci. 2020;7(Suppl 1):S23-30. https://doi.org/10.1016/j.jnss.2020.07.006 PMid:32995376

15. Gabriel EH, Mccann RS, Hoch MC, Cramer RJ. An intervention based on the health belief model led to improvements in selfefficacy towards ERIPP participation and functional performance in club sport athletes: A pilot study. J Sci Med Sport.
2020;23(10):921-6. https://doi.org/10.1016/j.jsams.2020.04.002 PMid:32402758

16. Lee H, Ho P, Wang W, Hu C, Lee C, Huang HL. Effectiveness of a health belief model intervention using a lay health advisor strategy on mouth self-examination and cancer screening in remote aboriginal communities: A randomized controlled trial. Patient Educ Couns. 2020;102(12):2263-9. https://doi. org/10.1016/j.pec.2019.07.001

PMid:31300183 